\title{
ANALISIS TERAPI MUSIK KLASIK DALAM RELAKSASI PERSALINAN DI BPM ERNIWATY DI BABAT SUPAT TAHUN 2018
}

\author{
Faulia Mauluddina ${ }^{1}$, Evi Epriyanti ${ }^{2}$ \\ Program Studi DIV Kebidanan STIKES Mitra Adiguna \\ Komplek Kenten Permai Blok J 9-12 Kelurahan Bukit Sangkal Palembang \\ Email : faulia.mauluddina@gmail.com
}

\begin{abstract}
Abstrak
Persalinan merupakan proses pergerakan keluanya janin, plasenta, dan membran dari dalam rahim melalui jalan lahir. Tujuan penelitian Untuk Menganalisis Terapi Musik Klasik Dalam Relaksasi persalinan. Penelitian ini mempergunakan data primer berupa dua orang ibu sebagai partisipan dimana satu ibu akan diberikan terapi musik dan ibu yang lain tidak diberikan terapi musik. Sampel dalam penelitian ini di tentukan secara purposive sebanyak dua orang ibu. Dari hasil penelitian yang dilakukan di BPM Erniwaty Babat Supat tahun 2018, "Mengenai Pengarauh Terapi Musik Klasik Dalam Merileksasi Persalinan”, maka Ibu yang dilakukan terapi musik klasik dan yang tidak dilakukan terapi musik klasik ada perbedaannya. Karena ibu yang di lakukan terapi lebih merasa tenang, nyaman dan rileks karena terahlinya perasaan takut dan cemas ibu tersebut pada terapi yang ia jalankan walaupun itu sudah mau mendekati proses persalinan, beda hal nya dengan ibu yang tidak dilakukan terapi musik klasik tersebut dia masih merasa cemas dan takut karena sudah mendekati proses persalinan, dapat disimpulkan Ibu yang dilakukan terapi musik klasik dan yang tidak dilakukan terapi musik klasik ada perbedaannya, saran nya Agar dapat melakukan terus terapi musik klasik terhadap ibu yang akan melahirkan bukan hanya pada ibu yang akan melahirkan tetapi ibu hamil pun dilakukan terapi musik tersebut.
\end{abstract}

Kata kunci

: Terapi Musik Dan Rileksasi Persalinan

Bahan Bacaan

: 21 (2009-2017)

\begin{abstract}
Labor is the process of moving both the fetus, placenta, and membrane from the uterus through the birth canal. Research Objectives To Analyze Classical Music Therapy in Labor Relaxation. This study uses primary data in the form of two mothers as participants where one mother will be given music therapy and the other mother will not be given music therapy. The sample in this study was determined purposively as many as two mothers. From the results of research conducted at Erniwaty Babat Supat's BPM in 2018, "Regarding the Influence of Classical Music Therapy in Relaxing Childbirth", the mother who performed classical music therapy and who did not do classical music therapy was different. Because mothers who do therapy feel more calm, comfortable and relaxed because the terahlinya feeling of fear and anxiety of the mother on therapy that he runs even though it already wants to approach the birth process, different from the case with mothers who are not done classical music therapy, he still feels anxious and fear that because it is approaching the delivery process, you can conclude that a classical music therapy is done and that there is no difference in classical music therapy, the advice is to continue classical music therapy for mothers who will give birth not only to mothers who give birth but pregnant women music therapy was carried out.
\end{abstract}

Keywords : Music Therapy and Relaxation of Labor Reading Material : 21 (2009-2017) 


\section{PENDAHULUHAN}

Persalinan adalah proses membuka dan menipisnya serviks dan janin turun kejalan lahir persalinan dan kelahiran normal adalah proses pengeluaran janin yang terjadi pada kehamilan cukup bulan (37-42 minggu) lahir spontan dengan presentasi belakang kepala, tanpa komplikasi baik ibu maupun janin. (Asri, 2012)

Kehamilan pada wanita dibedakan yaitu kehamilan primigravida (seorang ibu sedang hamil untuk pertama kali), multigravida (seorang ibu yang pernah hamil lebih dari 1 sampai dengan 5kali) dan grandemultiravida (seorang ibu yang pernah hamil lebih dari 5 kali). Ketika menghadapi proses persalinan pada tingkatan-tingkatan itu ibu tetap cenderung mengalami kecemasan.

Pada ibu primigravida, hampir semuanya mengalami kekhawatiran, kecemasan, dan ketakutan baik selama hamil, saat menghadapi persalinan, maupun setelah persalinan, namun kecemasan yang mereka rasakan umumnya berkisar mulai dari khawatir tidak bisa menjaga kehamilan sehingga janin tidak bisa tumbuh sempurna, khawatir keguguran, takut sakit saat melahirkan, takut bila nanti di jahit, bahkan lebih ekstrim lagi takut terjadi komplikasi pada saat persalinan sehingga dapat menimbulkankematian. Kekhawatiran yang tidak rasional pun sering kali muncul dibenak ibu hamil, apalagi ibu primigravida atau secoud (pernah hamil sebelumnya) yang pernah merasakan trauma persalinan, yang biasanya mengalami kecemasan saat mendekati harinya. Bagi sebagian wanita, proses melahirkan identik dengan pristiwa yang menakutkan, menyakitkan, dan lebih menegangkan dari pristiwa manapun dalam kehidupan. Dan adalah tugas bidan/dokter untuk mengatasi dan membantu mengurangi kecemasan yang dirasakan klien. (Aprillia, 2010)

Terdapat beberapa faktor yang mempengaruhi proses persalinan yaitu kontraksi (His) dan mengedan (power), jalan lahir (passage), janin dan plasenta (passanger), psikologis, dan penolong (provider), faktor-faktor tersebut sangat berperan dalam menentukan lancar atau tidaknya suatu persalinan. Contohnya saja persalinan memanjang, hal ini disebabkan oleh melemahnya kekuatan his dan mengedan ibu yang terkait dengan usia yang relative tua, salahnya pimpin pesalinan ataupun perasaan takut dan cemas, takut ataupun khawatir merupakan hal yang wajar terutama pada persalinan primigravida. (Karlita, 2013)

Musik klasik adalah sebuah komposisi musik yang dilahirkan dari budaya eropa sekitar tahun 1750-1825. Musik klasik bermanfaat untuk membuat seseorang menjadi rileks, menimbulkan rasa aman dan sejahterah, melepaskan rasa gembira dan sedih, menurunkan tingkat kecemasan pasien dan melepaskan rasa sakit dan menurunkan tingkat stress. (Musbikin, 2009)

Pengaruh musik klasik terahadap relaksasi kecemasan musik di yakini dapat digunakan untuk relaksasi, meringankan stress,dan mengurangikecemasan karena musik merupakan sebuah rangsangan pendengaran yang terorganisasi, yang terdiri atas melodi, ritme, harmoni, bentuk dan gaya. Ada salah satu cara dalam mengurangi kecemasan, salah satunya dengan mendengarkan musik Mozart/musik klasik. Musik klasik adalah musik yang mampu memperbaiki konsentrasi, ingatan dan persepsi sosial. (Haruman, 2013)

Dari hasil observasi secara hipotesis Somoyani menyatakan bahwa dari uji hipotesis yang digunakan uji-t dua sampel berpasangan pada musik tradisional Bali karena data berdistribusi normal, sedangkan musik klasik dan kontrol digunakan uji Wilcoxon karena data tidak berdistribusi normal. Selajutnya dilakukan uji analysis of variance (ANOVA) dengan hasil nilai $p=0,00$, dilanjutkan dengan analisis post hoc, yaitu uji mam whitney dengan hasil antara kelompok musik klasik dan kontrol nilai $p=$ 0.001, kelompok musik Bali dengan kelompok kotrol $p=0,020$. Hal tersebut menunjukan adanya perbedaan nyeri 
persalinan setelah mendengarkan musik klasik Mozart dibandingkan dengan kelompok kontrol, sama halnya dengan setelah mendengar musik tradisional Bali dibandingkan kelompok kontrol. (Somoyani dkk, 2017)

Dari uraian latar belakang dan observasi, diatas maka penulis tertarik melakukan penelitian mengenai "Analisis Terapi Musik Klasik Dalam Relaksasi Persalinan Di BPM Erniwaty Di Babat Supat Tahun 2018"

Tujuan Penelitian ini Telah Dianalisis Terapi Musik Klasik Dalam Relaksasi persalinan

\section{METODE}

Penelitian ini menggunakan pendekatan kualitatif, yang dilakukan pada bulan April - Juli 2018. Penelitian ini di fokuskan pada relaksasi persalinan yang menerapkan metode relaksasi dengan mempergunakan musik klasik. Relaksasi yang dimaksud merupakan adalah upaya menghilang rasa cemas atau rasa takut yang selalu dialami oleh ibu primigravida dalam persalinan. Musik klasik yang diterapkan adalah Mozart, musik tradisonal Bali, dan lain sebagainya yang nanti dari kenyataan dapat menurunkan rasa kecemasan, takut dan membuat rileks pada ibu bersalin tersebut.

Situasi sosial dalam penelitian ini adalah ibu bersalin di BPM Erniwaty Didaerah Babat Banyuasin Kecamatan Babat Supat. Selain itu juga dua orang partisipan kunci yang dipilih dari ada psikolog maupun bidan.

Sampel dalam penelitian ini di tentukan secara purposive sebanyak dua orang ibu dimana salah seorang ibu akan diterapi musik klasik dan yang lainnya tidak dilakukan terapi tersebut. Selain itu secara purposive juga dilakukan untuk menentukan partisipan kunci yaitu seorang psikolog dan seorang bidan senior yang berpegalaman lebih dari sepuluh tahun.

Penelitian ini mempergunakan data primer berupa dua orang ibu sebagai partisipan dimana satu ibu akan diberikan terapi musik dan ibu yang lain tidak diberikan terapi musik. Kedua nya akan diamati untuk melihat apakah terjadi perbedaan rasa cemas dan takut pada waktu persalinan berlangsung.

Pada kedua ibu itu akan dilakukan wawancara mendalam untuk mengetahui terapi tersebut berhasil atau tidak. Selain dipergunakan juga data primer selain itu digunakan data primer yang lain berupa psikolog dan bidan sebagai partisipan kunci. Pengumpulan data pada ke empat orang terseebut baik partisipan kunci maupun biasa dengan cara wawacara mendalam untuk memperoleh informasi-informasi yang dapat dipergunakan untuk analisis.

Penelitian ini juga memerlukan data sekunder yang diperoleh dari buku-buku teori, jurnal-jurnal, catatan-catatan diperpustakaan, catatan-catatan dinas kesehatan dan lainnya.

\section{HASIL PENELITIAN DAN PEMBAHASAN}

Pertanyaan 1 : Berapakah usia kehamilan ibu?

Jawaban :

"usia kehamilan saya sudah sembilan bulan lebih" (Ny Sv)

"usia kehamilan saya sudah sembilan bulan lebih" (Ny W)

Usia kehamilan kedua ibu partisipan ini sudah memasuki usia kehamilan yang aterm dan sudah seharusnya melahirkan.

persalinan adalah proses membuka dan menipisnya serviks dan janin turun kejalan lahir. Persalinan dan kelahiran normal adalah proses pengeluaran janin yang terjadi pada kehamilan cukup bulan (37-42 minggu) lahir spontan dengan presentasi belakang kepala, tanpa kompikasi baik ibu maupun janin. Asri (2012)

Sedangkan menurut bidan menyatakan bahwa persalinan merupakan proses pengeluaran janin dan plasenta secara spontan dengan usia kehamilan yang aterm atau usia kehamilan Sembilan bulan sepuluh hari yang tanpa ada komplikasi baik ibu 
maupun janin selama kehamilan dan persalinan.

Dari penjelasan diatas bahwa persalinan itu merupakan proses membuka dan menipisnya serviks dan proses pengeluaran janin dan plasenta secara spontan terjadi padaa usia kehamilan (37-42 minggu ) dengan tidak adanya komplikasi baik ibu maupun janin, jadi usia kedua partisipan diatas termasuk usia kehamilan yang aterm dan memang waktunya untuk melahirkan.

Pertanyaan 2 : Melahirkan anak keberapa? Jawaban :

"Saya Melahirkan Anak Pertama Saya karena saya sebelumnya belum pernah hamil atau pun melahirkan" (Ny Sv) "Saya Melahirkan Anak Pertama karena saya belum pernah hamil sebelumnya" (Ny $\underline{W}$.

Pada kedua partisifan ini sama-sama melahirkan anak pertama tidak pernah melahirkan sebelumnya, ataupun tidak pernah keguguran sebelumnya atau sering disebut ibu primigravida. Menurut bidan ahli bahwa ibu yang belum pernah melahirkan adalah ibu primigravida atau primipara.

Primigravida adalah keadaan di mana seorang wanita mengalami masa kehamilan untuk pertama kalinya. Manuaba (2010)

Menurut bidan ibu primigravida itu adalah ibu yang pertama kali hamil dan belum pernah melahirkan sebelumnya dan ini pertama sekali dia untuk mejalankan proses persalinan.

Dari hasil diatas bahwa ibu yang menjadi partisipan dalam penelitian ini adalah ibu yang baru partama kali hamil dan pertama kalinya melahirkan hal ini sesuai dengan teori yang telah di jelaskan

Pertanyaan 3 : Apa yang ada ketahui tentang terapi musik klasik dalam merelaksasi pada proses persalinan?

Jawaban :

Sebelumnya saya belum mengetahui apa itu terapi musik klasik. Tetapi setelah saya menjalani terapi musik tersebut saya merasakan lebih enak tidak terlalu cemas dan saya bisa tidur pada saat sakitnya datang tapi tidak terlalu saya rasakan karena saya fokus mendengarkan musik itu $(\mathrm{NySv})$.

Terapi musik itu merupakan intervensi alami invasive yang dapat diterapkan secara sederhana tidak selalu membutuhkan kehadiran ahli terapi, harga terjangkau dan tidak menimbulkan efek samping. Samuel (2010)

Terapi musik adalah suatu terapi kesehatan menggunakan musik dimana tujuannya adalah untuk meningkatkan atau memperbaiki kondisi fisik, emosi, kognitif, dan sosial bagi individu dari berbagai kalangan usia. Suharti (2008)

Musik klasik adalah komposisi musik yang lahir dari budaya eropa sekitar tahun 1750-1825. Musik klasik bermanfaat untuk membuat seseorang menjadi rileks, menimbulkan rasa aman dan sejahtera, melepaskan rasa gemira dan sedih, menurunkan tingkat kecemasan pasien pra operasi dan melepaskan rasa sakit dan menurunkan tingkat stres. Musbikin (2009)

Dapat disimpulkan bahwa dari yang dijelaskan Musik klasik bermanfaat untuk membuat seseorang menjadi rileks, meimbulkan rasa aman dan sejahtera, melepaskan rasa gemira dan sedih, menurunkan tingkat kecemasan pasien hal ini satu pedapat dengan yang dirasakan oleh pasien yaitu ibu merasakan lebih enak tidak terlalu cemas dan ibu bisa istirahat pada saat tidak ada kontraksi dan pada saat kontraksi persalinan tidak terlalu dirasakan karena fokus pada terapi tersebut sama halnya dengan pendapat bidan dan psikolog bahwasanya terapi musik klasik dalam merileks persalinan berpengaruh kenapa karena dapat memperbaiki kodisi fisik, mental, kognitif pada ibu dan ibu bisa mengahlikan perasaan takut dan cemas dengan mendengarkan terapi musik klasik tersebut.

Pertanyaan 4: Apakah manfaat nya saat dilakukan terapi musik klasik ?

Jawaban : 
Kalau menurut saya manfaatnya saya lebih merasa tenang dan tidak terlalu merasakan kecemasan ( $\mathrm{Ny} \mathrm{Sv}$ ).

Pengaruh pemberian terapi musik klasik dalam menurunkan tingkat kecemasan ibu hamil menjelang persalinan menemukan bahwa pemberian terapi musik klasik dapat menurunkan tingkat kecemasan ibu hamil menjelang persalinan, musik klasik memiliki irama dan nada yang lembut yang dapat memeberikan efek ketenangan bagi pendengarnya malalui stimulasi gelombang alfa.

Ada beberapa manfaat terapi musik bagi ibu, janin dan bayi, bagi ibu hamil/ibu sesudah melahirkan maupun janin/bayi, terapi musik dapat menimbulkan reaksi psikologis, karena musik dapat menenangkan (relaksasi) dan juga memberikan rangsangan (stimulasi). Melalui kegiatan terapi musik dapat menyongsong masa depan bayi/anak yang lebih cemerlang, karena untuk menghadapi era globalisasi dibutuhkan individu-individu yang memiliki keterampilan "otak" akan lebih dihargai tinggi, dan sangat dibutuhkan bila dibandingankan dengan individu yang hanya mengandalkan kekuatan "otot". Kegiatan terapi musik dapat membantu ibu-ibu hamil agar tetap dapat mempertahankan keseimbangan antara kesehatan jasmani, pikiran, dan emosi. Maryunani (2011)

Manfaat terapi musik adalah Mampu menutupi bunyi dan perasaan yang tidak menyenangkan, Mempengaruhi pernafasan, Mempengaruhi denyut jantung, nadi dan tekanan darah manusia, Bisa mempengaruhi suhu tubuh manusia, Bisa menimbulkan rasa aman dan sejahtera dan bisa mempengaruhi rasa sakit. Djohan (2010)

Dari hasil penelitian diatas manfaat dari terapi musik klasik bagi ibu yang akan melahirkan menurut teori yang menyatakan terapi tersebut dapat menurunkan tingkat kecemasan ibu hamil menjelang persalinan menemukan bahwa pemberian terapi musik klasik dapat menurunkan tingkat kecemasan ibu hamil menjelang persalinan, musik klasik memiliki irama dan nada yang lembut yang dapat memberikan efek ketenangan bagi pendengarnya. Hal ini sependapat dengan apa yang di rasakan oleh ibu yang diakukan terapi tersebut yakni ibu lebih merasakan ketenangan dan tidak terlalu merasa kecemasan seperti sebelumnya. karena bisa menimbulkan perasaan nyaman, aman, sejahtera dalam kodisi tersebut dapat mempengaruhi kondisi denyut jantung, nadi dan tekanan darah pada ibu jadi ibu bisa merasakan ketenangan dalam menghadapi proses persalinannya nanti.

Pertanyaan 5 :Apakah pengaruh terapi musik klasik terhadap proses persalinan ?

Jawaban :

Menurut saya ada pengaruhnya terapi tersebut karena sebelum saya di terapi musik klasik perasaan saya tidak tenang terus saat mau tidur saya tidak tenang jika sakitnya datang, beda pada saat saya di terapi oleh bidan dengan menggunakan yang di letakan di telinga saya, saya merasakan lebih sedikit tenang ddan tidak terlalu dirasakan pada saat sakit nya datang ( $\mathrm{Ny} . \mathrm{Sv}$ ).

Besarnya peran faktor psyche mendorong berbagai tindakan nonfarmakologis untuk membatu persalinan kala I yang berperan penting terhadap peralinan kala II. Salah satunya yaitu terapi musik. Terapi musik adalah pengunaan musik sebagai alat terapi untuk mempebaiki, memelihara, dan meningkatkan keadaan mental, fisik, dan emosi terapi musik juga cara yang mudah yang bermanfaat positif bagi tubuh psikis, serta meningkatkan daya ingat dan hubungan sosial. Djohan (2010)

Terapi musik dalam persalinan adalah suatu bentuk kegiatan yang menggunakan musik dan lagu/nyanyian secara terpadu dan terarah didalam membimbing ibu selama menghadapi persalinan untuk mencapi tujuan relaksasi bagi ibu saat nyeri kontraksi yang dirasakan atau dengan mengunakan earphone sesuai dengan musik yang disukai ibu seperti lagu rohani, alunan ayat al-Qur'an atau musik Mozart dan musik klasik lainnya. Metode terapi musik pada ibu yang 
menjelang persalinan akan sangat bermanfaat bagi ibu dalam mengahlikan rangsang nyeri saat kontraksi yang dirasakan, tetapi dengan ambang nyeri tergantung dengan mekanisme pertahanan diri ibu. Oleh karena itu perlunya persiapan ibu secara fisik dan mental yang baik ibu dalam menanti buah cinta kasih yang sehat sehingga nanti mempererat keharmonisan keluarga.

Jadi kesimpulannya Terapi musik yang dilakukan pada saat proses persalinan itu sangat berpengaruh karena bisa membuat ibu merasakan ketenangan, rileks dan tidak terlalu merasakan kecemasan dalam menghadapi persalinan karena adanya keahlian perhatian ibu pada saat sakit kontraksi dan proses pesalinan, sedangkan pada ibu yang tidak menggunakan terapi musik ibu tersebut masih merasakan kecemasan yang terlihat dari wajah dan tingkah ibu yang tidak bisa diam pada saat adanya kontraksi dan saat proses persalinan hal ini sesuai dengan pendapat para ahli menyatakan penggunaan musik sebagai alat terapi untuk memperbaiki, memelihara, dan meningkatkan keadaan mental, fisik, dan emosi terapi musik juga cara yang mudah yang bermanfaat positif bagi tubuh psikis, serta meningkatkan daya ingat dan hubungan sosial.

Pertanyaan 6 :Bagaimana pengaruh musik klasik terhadap kecemasan pada ibu bersalin?

\section{Jawaban :}

Kalau saya belum terlalu tahu apa penguhnya tetapi yang saya rasakan memang kecemasan yang saya rasakaan sedikit berkurang dan tidak terlalu takut pada saat persalinan (NY.E).

Musik di yakini dapat digunakan untuk relaksasi, meringankan stress, dan mengurangi kecemasan karena musik merupakan sebuah rangsangan pendengaran yang terorganisasi, yang terdiri atas melodi, ritme, harmoni, bentuk dan gaya. Ada salah satu cara dalam mengurangi kecemasan, salah satunya dengan mendengarkan musik Mozart/musik klasik. Musik klasik adalah musik yang mampu memperbaiki konsentrasi, ingatan dan persepsi sosial. Haruman (2013)

Pengaruh terapi musik klasik terhadap kecemasan persalinan dari penjelasan diatas menyatakan bahwa ada pengaruh terapi musik, kecemasan pada proses kelahiran karena bisa membuat ibu merasa rileks dan tenang beda yang dirasakan pada ibu yang tidak dilakukan terapi musik tersebut, hal ini sesuai dengan penelitian yang dilakukan bahwa rasa kecemasan yang saya rasakan sedikit berkurang dan rasa sakit yang dirasakan pada saat kontraksi juga tidak terlalu dirasakan dan pasien terlalu takut pada saat persalinan walaupun ini persalinan yang pertama.

Pertanyaan 7 : kapan waktu dilakukan terapi musik klasik ?

\section{Jawaban :}

Menurut saya sebenernya terapi musik itu harusnya dilakukan pada saat ibu hamil karena banyak sekali manfaat dari dilakukan terapi musik karena bukan hanya untuk ibu untuk janin pun sangat bermanfaat karena bisa menjaga kesejahteraan janin didalam kandungaan.( BD.E).

Waktu pelaksanaanbagi ibu hamil untuk mengikuti terapi musik, sebaikbaiknya Sejak kehamilan 10 minggu atau 16 minggu -20 minggu, ibu hamil mengikuti terapi musik, minimal $1 \mathrm{X}$ seminggu, Pada kehamilan 21 minggu -30 minggu, ibu hamil mengikuti terapi musik, minimal $2 \mathrm{X}$ seminggu, Pada kehamilan 31 minggu - 36 minggu, ibu hamil mengikuti terapi musik minimal 3X semiggu, dan Pada kehamilan 37 minggu - 40 minggu / 41 minggu atau sampai dengan lahir, sebaiknya ibu hamil mengikuti terapi musik setiap dengan lahir, sebaiknya ibu hamil mengikuti terapi musik setiap hari. Haruman (2013)

Waktu dalam melakukan terapi musik klasik itu yang diperlukan untuk terapi adalah 30 menit, untuk merelaksasi (10-15 menit), dan stimulasi (15-20 menit). Dirumah, lamanya dengar musik yang 
dianjurkan untuk ibu hamil sekitar 30 menit per hari.

Jadi dari penjelasan dari beberapa teori menyatakan bahwa Waktu pelaksanaan terapi musik klasik itu sebaiknya dari semenjak kehamilan 10 minggu dan sampai dengan lahir dan mengikuti terapi tersebut setiap hari. akan tetapi di penelitian ini terapi musik klasik di mulai pada saat proses menjelang persalinan sampai lahirnya bayi. Setelah di teliti memang Ternyata ada pengaruh terhadap merileksasi ibu pada saat menjelang persalinan apalagi pada ibu primigravida, karena ibu yang pertama kali melahirkan itu pasti ada rasa kecemasan pada saat akan melahirkan hal sependapat dengan pernyataan diatas. Oleh sebab itu perlu dilakukan terapi non- farmakologis seperti terapi musik klasik tersebut ternyata membuat ibu yang akan melahirkan apalagi ibu primigravida mengalami rileks dan tenang dalam menghadapi pesalinannya, akan tetapi terapi ini bukan hanya pada ibu primigravida saja melainkan untuk semua ibu hamil. Tapi di penelitian ini terapi musiknya dilakukan pada saat kala I fase aktif pada saat bukaan $8 \mathrm{~cm}$, sampai kala II atau kala pengeluaran janin.

\section{DISKUSI}

Dari hasil observasi yang dilakukan pada ibu yang dilakukan terapi musik klasik bisa dibedakan karena ibu yang dilakukan terapi musik klasik lebih merasa rileks, nyaman, aman dan sejahterah dan bisa menurunkan kecemasan yang ada pada ibu tersebut dalam menghadapi proses persalinan karena bisa dilihat perbedaannya dengan ibu yang tidak dilakukan terapi musik tersebut, ibu yang tidak dilakukan terapi musik itu terlihat cemas, dan tidak nyaman saat mendekati proses persalinan. Jadi ibu yang dilakukan terapi musik klasik dapat berpengaruh terhadap merileksasi persalinan.

\section{SIMPULAN}

Dari hasil penelitian yang dilakukan di BPM Erniwaty Babat Supat dari 20 Juni - 10
Juli 2018, "Mengenai Analisis Terapi Musik Klasik Dalam Merileksasi Persalinan" di BPM Erniwaty Babat Supat tahun 2018, maka dapat disimpulkan.

Terapi musik klasik dapat berpengaruh terhadap merileksasi dalam persalinan. Karena terapi musik tersebut bisa menimbulkan perasaan nyaman, aman tenang, damai, sejaterah dan dapat menurunkan tingkat kecemasan pada pasien/ ibu yang akan melahirkan.

\section{SARAN}

Agar dapat melakukan terus terapi musik klasik terhadap ibu yang akan melahirkan bukan hanya pada ibu yang akan melahirkan tetapi ibu hamil pun dilakukan terapi musik tersebut, bukan hanya pada ibu primigravida saja tetapi semua ibu hamil ataupun ibu melahirkan lainnya. Karena dengan terapi tersebut bisa membuat ibu lebih merasakan nyaman, tenang dan rileks dalam menghadapi persalinan jadi jika setiap ibu di terapkan terapi tersebut maka bisa menurunkan angka kecemasan ibu dalam menghadapi proses persalinan nantinya.

\section{DAFTAR PUSTAKA}

Aprillia, yesie. 2010. Hipnostetri Rileks, Nyaman Dan Aman Saat Hamil Dan Melahirkan. Jakarta. Gagas Media.

Asrinah. 2010. Asuhan Kebidanan Masa Persalinan. Yogyakarta: Graha Ilmu.

Bassano M. 2009. Terapi Musik Dan Warna. Yogyakarta: Rumpun.

Djohan. 2010. Terapi Musik Teori Dan Aplikasi. Galangpress: Yogyakarta.

Haruman. 2013. Pengaruh Terapi Musik Klasik Terhadap Penurunan Kecemasan Atlet Sebelum Menghadapi Pertandingan. Skripsi. Universitas Diponogoro Semarang. 
Maryunani. Anik. 2010. Nyeri Dalam Persalinan (Tehnik Dan Cara Penangananya).Jakarta: CV. Trans Info Media.

Musbikin. I. 2009. Kehebatan Musik Untuk Mengasah Kecerdasan Anak. Power Books (IHDINA): Jakarta.

NK Somoyani, Dkk. 2017. Pengaruh Terapi Musik Klasik Dan Musik Tardisional Bali Terhadap Intensitas Nyeri Persalinan Kala I Fase Aktif. Jurnal Bahana Kesehatan Masyarakat Vol. 1 No. 1.

Samuel. 2010

http//www.fortunecity.com./skyscraper/p roxy/596/Indonesia/depresi/terapitanpao bat.htmdiaskes tangga 3 april 2014.

Suhartini. 2008. Effectiveness Of Music Therapy Toword Reducing Patient's Anxienty In Intensive Care Unit. Jurnal Ilmiah Kesehatan. Vol. 2 No. 1. 